ES/ER/TM- - -33

DE92 019010

\title{
Approach and Strategy for Performing Ecological Risk Assessments for the Department of Energy Oak Ridge Field Office Environmental Restoration Program
}

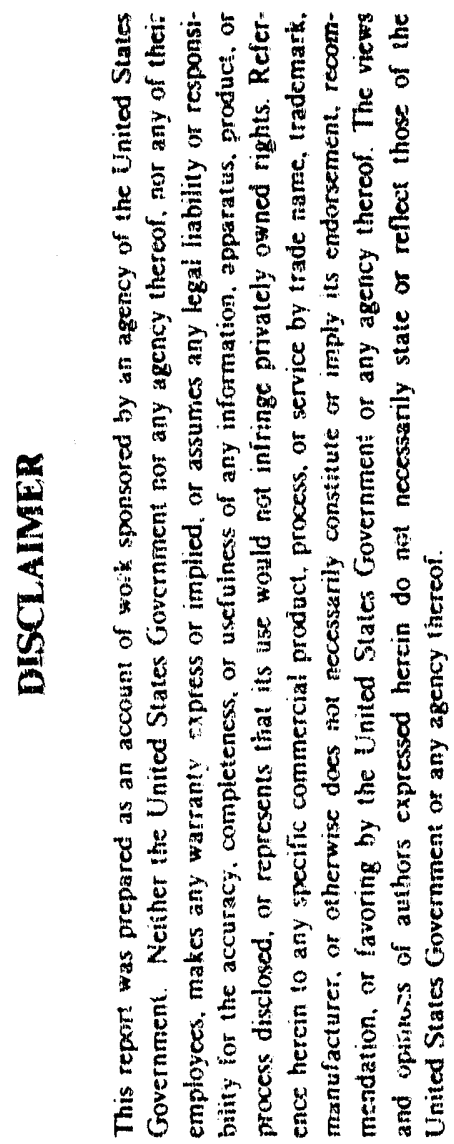

\author{
Environmental Restoration Division \\ P.O. Box 2003 \\ Oak Ridge, Tennessee 37831-7256
}

Date Issued-July 1992

Prepared by

Environmental Sciences Tivision and

Health and Safety Research Division Oak Ridge National Laboratory

Oak Ridge, T"ennessee ESD Publication 3906

\section{Prepared for}

U.S. Department of Energy

Office of Environmental Restoration and Waste Management under budget and reporting code EW 20

MARTIN MARIETTA ENERGY SYSTEMS, INC. managing the

Ouk Ridge K-25 Site

Oak Ridge Y-12. Plant

Oak Ridge National Laboratory under contract DE-ACO5-84OR?i400
Paducah Gaseous Diffusion Plant Portsmouth Gaseous Diffusion Plant under contract DE-AC05-760RDO001

for the

U.S. DEPARTMENT OF ENERGY

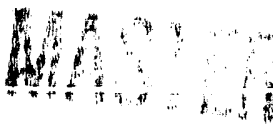




\section{Authors}

G. W. Suter II

A. Redfearn

R. K. White

R. A. Shaw

\section{Author Affiliations}

G. W. Suter II is a member of the Environmental Sciences Division. A Redfearn, R. K. White, and R. A. Shaw are members of the Health and Safety Research Division. Both of these divisions are part of Oak Ridge National Labonatory, Martin Marietta Energy Systerns, Inc. 


\section{CONTENTS}

ACKNOWLEDGMENTS $\ldots \ldots \ldots \ldots \ldots \ldots \ldots \ldots \ldots \ldots \ldots \ldots \ldots \ldots$

EXECUTTVE SUMMARY $\ldots \ldots \ldots \ldots \ldots \ldots \ldots \ldots \ldots \ldots \ldots$ vii

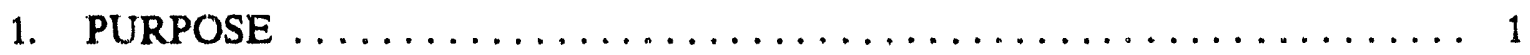

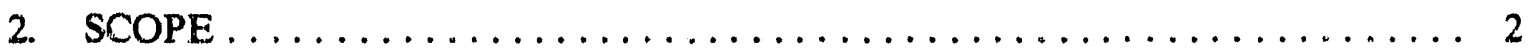

3. ORGANIZATION OF ECOLOGICAL RISK ASSESSMENT ACTIVTTIES . . . 3

4. INITIAL SCOPING PHASE: HAZARD DEFINITION $\ldots \ldots \ldots \ldots \ldots \ldots \ldots$

4.1 RECEIVING ENVIRONMENT CHARACTERIZATION ........... 4

4.1.1. Operable units

4.1.2 Watersheds

4.1.3 Reservation-wide

4.2. IMPLICATIONS OF SCALE FOR ECOLOGICAL RISK

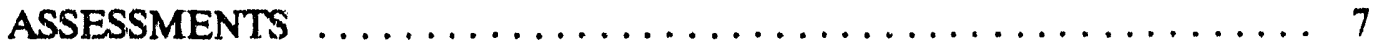

4.3 SOURCE CHARACTERIZATION $\ldots \ldots \ldots \ldots \ldots \ldots \ldots \ldots \ldots$

4.4 DEVELOPING ENDPOINTS FOR ECOLOGICAL RISK ........... . 9

4.5 PRELIMINARY VERSUS BASELINE ASSESSMENTS $\ldots \ldots \ldots \ldots \ldots, 10$

5. MEASUREMENT AND ESTIMATTON $\ldots \ldots \ldots \ldots \ldots \ldots \ldots \ldots \ldots \ldots \ldots$

6. RISK CHARACTERIZATION $\ldots \ldots \ldots \ldots \ldots \ldots \ldots \ldots \ldots \ldots \ldots \ldots \ldots \ldots \ldots \ldots$

6.1 DETERMINING WHETHER THE SITE POSES

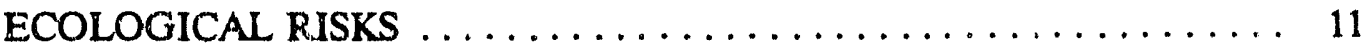

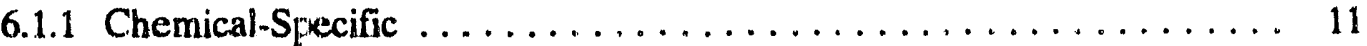

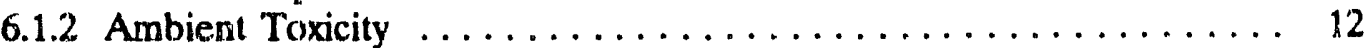

6.1.3 Biological Surveys ........................... 13

6.2 DETERMINING THE MAGNITUDE AND EXTENT OF

ECOLOGICAL EFFECTS ...................... 14

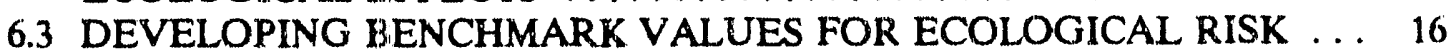

7. RISK CHARACTERIZATION $\ldots \ldots \ldots \ldots \ldots \ldots \ldots \ldots \ldots \ldots \ldots \ldots$

8. THE INTERFACE BIETWEEN ECOLOGICAL AND HUMAN HEALTH RISK ASSESSMENTS . . . . . . . . . . . . . . . . . . . . . . . . . . 19

9. IMPLEMENTATTON . . . . . . . . . . . . . . . . . . . 19

9.1 DEVELOP BENCHMARK VALUES FOR CONTAMINANTS OF CONCERN AT DOE-OR ER SITES . . . . . . . . . . . . . 19

9.2 COMPARE ECOLOGICAL AND HUMAN HEALTH BENCHMARKS .. 19

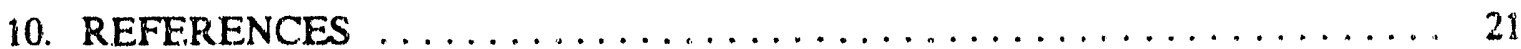




\section{ACKNOWLEDGMENTS}

The manuscript benefited from the review comments of Harry Boston and Larry Barnthouse. Discussions with Owen Hoffnian, Steve Bartell, and Larry Barnthouse helped to clarify the ideas. 


\section{EXECUTTVE SUMMARY}

This document is intended to supplement existing U.S. Environmental Protection Agency (EPA) guidance for ecological risk assessment at hazardous waste sites by providing guidance that is more specific and more tailored to U.S. Department of Er ergy sites than the guidance available from the EPA. However, it is a conceptual strategy document and does not include specific guidance on data, assumptions, and models. That detailed guidance is under development and will be presented in subsequent documents.

Ecological risk assessments are equal to human health risk assessments in regulatory importance and can use many of the same data and some of the same estimation methods. However, they also have peculiar data needs and methods. Ecological risk assessments begin with an initial scoping phase, termed hazand definition, that characterizes the sources, the potentially exposed environment, and the assessment endpoints. In the subsequent measurement and estimation phase, in which data are obtained concerning exposure of the endpoint biota to the contaminants and the effects of those exposures, and assumptions and models are used to relate the data to the desired exposure and effects parameters. Finally, in an integration phase, termed risk characterization, the various exposure and effects estimates are combined to infer the existence, cause, magnitude, and extent of effects of contaminants on the ecological endpoints. This phase is much more complicated for ecological risk assessments than for human health assessments because more types of data are available. Ecologicai risk assessments estimate effects using laboratory toxicity test results, like human heaith assessments, but also use results of ambient toxicity tests and biological surveys.

Ecological risk assessments will be performed in an iterative hierarchical manner. The lowest level is the individual waste site or source control operable unit (OU). These sites typically have little ecological significance in themselves but constitute the source of release of contaminants to the wider environment. Integrator OUs receive and integrate the releases from multiple waste sites and other sources of contaminants or disturbance. For aqueous contaminants they are watersheds, and for terrestrial contaminants they are entire reservations. Causes of effects in integrator OUs are traced to source control OUs, and the significance of releases from source control OUs must be defined by their effects on integrator OUs. 


\section{PURPOSE}

Although ecological risks are equal to human health risks in regulatory inportance (Reilly 1990, SAB 1990), formal procedures for ecological risk assessment are poorly developed. This state of affairs is reflected in the U.S. Environmental Protection Agency's (EPA's) risk assessment guidance manual for ecological risk assessments (EPA 1989), which addresses procedures and general philosophy but provides no concrete guidance. This report will provide specific guidance and promote the use of consistent approaches for ecological risk assessments at individual Department of Energy, Oak Ridge Field Office, Environmental Restoration (DOE-OR ER) Division sites. The strategy discussed in this report is consistent with the overall strategy for site management and Comprehensive Environmental Response, Compensation, and Liability Act (CERCLA) compliance developed for the Oak Ridge Reservation (ORR) (Environmental Restoration Division 1992). 


\section{SCOPE}

An ecological risk assessment includes estimation of transport, transformation, and accumulatio $n$ of contaminants in ecosystems; estimation of exposure of organisms to contaminants in ambient media and food; and estimation of effects of contaminant exposure on nonhuman organisms and ecosystem processes. The general strategy for performing ecological risk assessments at DOE-OR ER sites will be consistent with EPA guidance (EPA 1989 and Warren-Hicks et al. 1989). As far as possible, the strategy will parallel practice in human health risk assessments, but it will be more complex because effects can be measured directly in the nonhuman biota by monitoring natural communities and by performing ambient toxicity tests (Sect. 6.1). 


\section{ORGANIZATION OF ECOLOGICAL RISK ASSESMENT ACTIVITIE:}

Risk assessments for hazardous waste sites can be divided into four phases: (1) an initial scoping phase, termed hazard definition; (2) a measurement and estimation phase; (3) an integration phase that estimates risks, and (4) a risk characterization phase. These phases will be discissed in turn in the following sections. Where preliminary screening assessments and baseline assessments differ, those differences will be pointed out. 


\section{INITIAL SCOPING PHASE: HAZARD DEFINITION}

Hazard definition requires that the source, the nature and extent of the potentially exposed environment, and the assessment endpoints be characterized. These activities must be carried on concurrently because they are interdependent. The results of the hazard definition should constitute a conceptual model of the form: defined contaminant releases are believed to move through the environment a predictable manner potentially resulting in exposure of defined endpoint biota and subsequent effects.

\subsection{RECEIVING ENVIRONMENT CHARACTERIZATION}

Receiving environment characterization involves describing the types of biotic com:nunities present, the potential endpoint species present, and the distribution of communities and populations relative to the source and routes of transport. These activities are briefly discussed in EPA (1989) and Warren-Hicks et al. (1989); however, the EPA guidance does not address the issue of how to treat the hierarchy of scales of environmental exposure created by the distribution of sites within a landscape. This topic is discussed in the following paragraphs.

Procedures for ecologital risk assessments depend on the scale of the particular study and the species that will be considered. It would be futile to study the deer populations on individual operable units (OUs), for example, because the range of a deer population or even an individual deer is much larger than an operable unit. Similarly, if multiple OUs release contaminants to a stream, it would be misleading to assess the risks to the stream resulting from those individual sources. However, some endangered or threatened species or critical habitats may be assessed on these small spatial scales, and the inputs of each OU to the larger scale assessment must be estimated. Thus, before protocols can be established for ecological risk assessments, the scale of the studies to be performed must be considered, and an organizational plan for activities at DOE-OR ER sites that pose potential ecological threats must be proposed.

Ecological risk assessments will be performed on three levels:

1. discrefe operable units,

2. watersheds, and

3. reservation-wide.

Because of contamination resulting from past waste releases, many of the watersheds themselves operable units. The need to integrate risk assessments at different scales has resulted in establishment of a distinction between source control operable units, which are the waste disposal sites, and integrator operable units, which are the watersheds and groundwater bodies that integrate the releases from the individual sites. Assessment of the integrator OUs indicates the significance of the ongoing releases from the source control OUs. However, the significance of contaminants in the integrator OUs cannot be determined until the source control OUs have been remediated so that residual exposure and effects in the integrator OUs are apparent. For this reason, the assessments of source control and integrator OUs 
must be integrated into an iterated hierarchy of assessments and remedial actions (Environmental Restoration Division 1992).

The need for an ecological risk assessment at individual OUs will be determined on a site-by-site basis. Risk assessments performed for a particular watershed should generally be performed concurrently with the risk assessments for those OUs that are likely to be relevant to that watershed. Those are the OUs that occur within the watershed and are thought to release contaminants to the surface waters, rooting zone ground waters, floodplain soils, or other media of that watershed to which biota are exposed. Reservation-wide risk assessment activities should be performed after all other activities have been completed (although field studies and modeling may be initiated earlier).

Information from small-scale assessments will be incorporated into the larger scale investigations, either providing source terms to calculate total cumulative risk from multiple sites, or identifying sources of contaminants found to have environmental impacts over large spatial scales.

\subsubsection{Operable units}

Because ecological risk assessments are normally concerned with the impacts of hazardous waste sites on populations rather than on individuals, and because individuals of many endpoint species have ranges larger than an individual $\mathrm{OU}$, detailed ecological risk assessments will generally not be warranted at individual OUs. However, in some cases, individual units may represent $\& \mathrm{n}$ ecological threat to a population. Therefore, during project scoping, the level of detail required for an ecological risk assessment will be determined, based on

1. The presence of federal or state listed endangered or threatened species and the possible impacts on these species.

2. The possibility that the site will have significant impacts on endpoint populations. This will depend on population sizes within the site relative to surrounding areas, the presence of breeding populations within the site, and the distribution and movements of individual organisms.

3. The nature of habitats present within the site. The presence of particularly valuable or sensitive protected habitats (e.g., wetlands) at a site may trigger a detailed risk assessment.

Based on these criteria, sites will be categorized into three groups. High priority sites will require an immediate detailed ecological risk assessment. These are sites that may adversely affect threatened or endangered species or protected habitats. Low priority sites will be considered on an as-needed basis. These sites either have natural vegetation, are temporarily devegetated and will be allower to return to natural or seminatural vegetation, or are used by wildlife but are thought to have no special significance for nonhuman populations. Screening risk assessments will be used to deiermine whether deiailed ecological studies are required. No inpact sites do not require any specific ecological investigations. These are sites that have no impact on nonhuman populations because they do not provide habitat for biota. This group will include underground storage tanks and asphalt storage pads. For such sites, a short section or chapter accompanying the human health risk assessment will justify the 
decision $r$ it to perform an ecological assessment, noting that if larger scale assessments identify ecological concerns, the possible contaminant releases from the individual site will be considered. Site characterization data and fate and transport models used for the individual site's human health risk assessment will be addressed to evaluate the site's potential for releasing contaminants that are of ecological concern over a large scale.

\subsubsection{Watersheds}

The various watersheds that have the potential to receive contaminants released from sites administered by DOE-OR ER will require detailed ecological evaluations (although initially, screening assessments will be utilized to prioritize contaminants and areas of study). Some of these watersheds have already been identified for the Oak Ridge Reservation (ORR), and in some cases Remedial Investigations are already underway or planned.

Since the OUs have been defined on a human health basis, it may prove that some contaminants of ecological concern in watersheds are difficult to trace back to the source. Thus, some additional individual sites releasing such contaminants may need to be characterized in order to determine the potential for releases to the watershed. For example, the cooling towers at the Oak Ridge Y-12 Plant have not been identified as OUs although they release chlorine, an ecologically hazardous chemicai, into East Fork Poplar Creek.

\subsubsection{Reservation-wide}

An assessment of the total environmental impacts from all hazardous waste sites on the ORR and at the Paducah and Portsmouth Gaseous Diffusion plants will be necessary. Reservation-wide studies are already underway for certain species, such as the white-tailed deer and the Canada goose on the ORR. Other species that may potentially be impacted by DOE-OR ER activities over large spatial scales will be identified. Trends in population densities will be monitored, as well as organismal and suborganismal characteristics such as growth rates, survivorship, condition, contamination levels, etc. Such data will be collected for risk assessments at certain OUs or watersheds, and this data will be incorporated in the reservation-wide database. Data from the Biological Monitoring and Abatement Program will also be incorporated.

\subsection{IMPLICATIONS OF SCALE FOR ECOLOGICAL RISK ASSESSMENTS}

Ecological risk assessments at OUs will concentrate on (1) plants (because they establish productive vegetation on the site), (2) endangered and threatened species (because effects on even a few individuals may be of concern), and (3) local populations of animals that may be significantly affected by toxic effects or remedial actions on the OU (because they constitute the habitat of a significant fraction of the population). The assessments will consider the site as an isolated unit, appraising the impacts on populations due to contamination only within the boundary of the unit. Off-OU releases of contaminants and effects on mobile and widely distributed species will be covered separately by the larger-scale studies. However, the $\mathrm{OU}$ assessments must define the input of their contaminants to the larger-scale exposures. 
The ecological risk assessments for watersheds will focus on the aquatic environments and floodplains. However, possible impacts on surrounding terrestrial systems will also be evaluated. Such impacts might result from disposal of dredge spoils or from rechanneling the stream. Ecological and human health risk assessments for individual OUs will be used to identify the sources of contaminants posing ecological hazards.

Because ecological impacts on aquatic systems will have been covered to a large degree in the watershed studies, the reservation or plant-wide ecological studies will focus on terrestrial components. The investigations will include the sampling of the various media in habitats of ecological concern not covered by the smaller scale studies, the monitoring of field populations of key species, and the use of models predicting fate and transpori processes as well as ecosystem and population processes. It is important to emphasize that these studies will look beyord the boundaries of DOE-OR ER sites. This would be the case for the deer that roam on and off the ORR, for example. Risk assessments for individual OUs will be used to identify the sources of contamination posing ecological hazards at the reservation-wide scale.

\subsection{SOURCE CHARACTERIZATION}

Source characterization depends on the nature and scale of the assessment. At an individual site $(\mathrm{C} J)$, the sources are leaking tanks, pits, trenches, spill-contaminated soil, etc. For a watershed, the sources are the runoff, seeps, and groundwater that transport contaminants from the sites to the watershed and the residues in the sediments and floodplain soils of the watershed from prior releases and point source effluents. For reservation-wide assessments, the sources are all the sources of contamination to which biota may be exposed. Sources that are not subject to Resource Conservation and Recovery Act (RCRA) or CERCLA regulation such as National Pollutant Discharge Elimination System (NPDES)-permitted waste water releises must still be characterized so that their contributions to ecological effects can be assessed and distinguished from the waste-related contamination.

Ideally, characterization would consis: of a source term-that is, an estimate of the rate of release of all contaminants from the disposal facility that is the ultimate source. At DOEOR ER sites however, source terms are very seldom available. Rather, the source that is characterized is the proximate source: the concentrations in water, sediments, and surface soils to which organisms are directly exposed.

\subsection{DEVELLPING ENDPOINTS FOR ECOLOGICAL RISK}

In order to determine whether the ecological risks posed by a site warrant remediation activities, the types and levels of ecologically harmful effects that are considered unacceptable at DOE-OR ER sites must be identified. This involves setting assessment endpoints, which are expressions of the environmental values that are to be protected (Suter 1989). There are no standard endpoints for ecological risk assessments equivalent to the probabilities of cancer and birth defects used in human heaith risk assessments. 
The EPA has been reluctant to establish ecological endpoints. There are no ecological endpoints specified in Risk Assessment Guidance for Sigperfund: Volume II. Environmental Evaluation Manual (EPA 1989) and the acconipanying field and laboratory referense manual (Warren-Hicks et al. 1989) only discusses criteria for choosing endpoints. "Therefore, the process of developing reference loxicity values for ecological risk assessments must begin by establishing asserssment endpoints.

The EPA's field and laboratory reference manual for ecological risk assessments indicates that assessment endpoints should be (1) socially relevant, (2) biologically relevant, (3) operationally definable, (4) measurable or predictable, (5) susceptible to the hazardous agent, and (6) logically related to the decision (Suter 1989). For these reasons, the following generic end points are pro; sed for ecological risk assessments of DOE-OR ER sites:

1. Any toxic effects on inditiduals of a threatened or endangered species sufficient to impair survival or reproduction.

2. A $20 \%$ or greater reduction in the abundance or production of a local population of selected speries of fish, bira, mammal or vasculai plant.

3. Darnage to wetlands or floodplains communities sutinzisnt ts cause los" of one of the following functions: (a) regulation of hydrology, (b) provision of habitat for wetland or loodplain dependent wildlife, or (c) processing of nutrient and contaminant chemicals.

Effects on species that are not included explicitly in the endpoints are nonetheless considered. For example, the only endpoint species in the aquatic community are fish, but the effects on foodchain species must be included in the assessment of risks tu fish. No species exists in isolation from the community of which it is a part

The principal endpoints are effects at the population rather than the individual level of biological organization. Unlize human health assessments, ccological risk assessments are not concerned with effects on individual organisms. The exception is threatened and endangered species. Endpoints are defined at the individual level for these species berause of the high level of legai and societal concern. Assessments of effects at higher levels of biologicial organization (i.e., communities and ecosystems) must primarily address physical disturbance because there is little information on toxic effects at these levels, and the toxicity data that. are available ane highly inconsistent. However, functional redundancy (the ability of a resistant species to perform the ecosystem functions formerly performed by a sensitive species that has been injured) tends to buffer ecosystem processes from toxic effects and the higher level taxa used as endpoint species tend to integrate the effects on ecosystem processes. In other words, if the tish populations are not affected, ecosystem processes are unlikely to have been significantly damaged.

The $20 \%$ level of population effects was ctiosen for two reasons. First, it is approximately the limit of detection of field measurement techniques, and it is probably below the detection limits of the public (i.e., fishermen would probably not notice a $20 \%$ reduction in the abundance of fish). For example, at least 20 years of data would be necessary to detect a $50 \%$ reduction in mean year-class strength of white perch in the Hudson River, even allowing a Type II ernor of $50 \%$ (Vaughan and Van Winkle 1982). The minimum detectable difference 
varies with species, habitat, and sampling sethod, but for mobile species viffe:ences of less than $20 \%$ can seldom be reliably detected.

The second reason for choosing a 20\% levei is that it is approximately the level of effect that corresponds to benchmarks used by the EPA and others, including the benchmark used most often for ecological assessments of waste sites, the Chronic National Ambient Water Quality Criteria for Protection of Aquatic Life (NWQC) (Office of Policy Analysis 1989). The NWQC are based on thresholds for statistically significant effects on individual responses of fish and aquatic invertebrates. Those thresholds correspond to approximately $25 \%$ reductions in the parameters of fish chronic issts (Suter al. 1987) and 20\% reductions in the parameters of fish "subchronic" tests (Anderson and Norberg-King 1991). Because of the compounding of individual responses across life stages, the chronic NWQC frequently correspond tis greater than $20 \%$ effects on populations (Barnthouse et al. 1990). The 20\% level would ulso be consistent with practice in assessments of terrestrial effects, bicause the Lowest-Observed.Effects-Concentration (LOEC) for dietary tests of avian reproduction (the most important chronic test endpoint for ecological assessment of terrestrial effects of pesticides and arguably the most applicable test for waste sites) corresponds to approximately a $20 \%$ effect on individual response parameters (Office of Pesticide Programs 1982). Hence, a jopulation effects level for scological assessment endpoints lower than $20 \%$ would result in benchmarks lower than current EPA practice and could not reliably be confirmed by field studies.

For some components of ecological risk assessment it may be necessary to designate a particular species as a surrogate for the group. The choice of specific species for individual assessments should be consistent with these generic endpoints and with the criteria for assessment endpoints found in the EPA's tield and laboratory reference manual for ecological risk assessments. In the Clinch River, for example, the largemouth bass might be chosen as a pelagic species because it is a top predator and is socially relevant, whereas the channel catfish might be chosen as a benthic species that is socially relevant.

\subsection{PR. LIMINARY VERSUS BASEIINE ASSESSMENTS}

For preliminary assessments, the hazard definition must be performed de novo with the principal purposes of the assessment being to produce a refined hazard definition for the baseline assessment and to define data gaps that should be filled prior to the baseline assessment. The preliminary assessment is often referred to as a screening assessment because it eliminates from further consideration components of the source that do not pose a hazard, endpoint biota that are not exposed to any contaminant in hazardous amounts, and portions of the site or of the wider environment where no hazardous exposures occur. Therefore, in the preliminary assessment the hazard definition should be as broad as is reasonably possible so that no potential hazards are overlooked. In contrast, the hazard definition for the baseline assessment should include only those hazards that have some credibility based on the preliminary assessment. 


\section{MEASUREMENT AND ESTIMATION}

Following the hazard definition phase, the risk assessment must derive estimates of sources, exposures, and effects. For preliminary (screening) assessments this is done by obtaining the results of prior measurements. For baseline assessments, new measurements are obtained to fill the data needs demonstrated by the preliminary assessment. In either case, some data will not be available and must be estimated. In particular, the bioavailable forms of chemicais often are not mearured and must be estimated. Methods for measuring exposure and effects were recommended by Warren-Hicks et al. (1989). 


\section{RISK CHARACTERIZATION}

After data have been collected and models have been run to characterize exposure and effects, these results must be integrated in a process termed risk characterization. This phase characterizes the nature and extent of ecological risks and organizes the results in a form that is useful for decision making concerning further investigations (preliminary assessments) or remedial actions (baseline assessments).

\subsection{DETERMINING WHETHER THE SITE POSES ECOLOGICAL RISKS}

Three approaches can be employed for assessing whether ecological risiss are posed by DOE-OR ER sites. They are equivalent to the chemical-specific approach, the effluent toxicity-based approach, and the biological approach used by the EPA Office of Water to set criteria for point sources (EPA 1990). Assessment reliability is greatly increased by combining evidence from all three approaches.

\subsubsection{Chemical Specific}

The least reliable method is the one used by human health assessments. That is, measurement of concentrations in ambient media and comparison of those concentrations to toxicological benchmark values derived from toxicity test data (Sect. 6.3). This method is particularly appropriate for preliminary screening assessments because data other than ambient concentrations are frequently unavailable. However, it does not reliably account for effects of mixtures, for variance among sites in bioavailability, and for chemicals for which good toxicity data are not available for all endpoints. This approach is mandated by CERCL A such that when applicable or relevant and appropriate requirements (ARARs) are exceeded, those exceedences must be identified. The ARARs that are relevant to ecological risk assessments are the NWQC and the equivalent state water quality standards (Office of Policy Analysis 1989). Other benchmarks need to be developed that better represent the endpoints (Sect. 9.1).

\subsubsection{Ambient Toxicity}

Ambient toxicity tests or laboratory tests of ambient media can be performed (Parkhurst et al. 1989, Green et al. 1988). These account for effects of chemical mixtures and bioavailability, but the species, life stages, and temporal patterns of exposure differ from natural exposures. In general, they do not indicate what contaminants are responsible for the toxicity, but the results of chemical-specific assessments can be used for that purpose. Tests of effluents and ambient waters have been conducted in many tatersheds for NPDES compliance. 


\subsubsection{Biological Surveya}

Potentially, the most relevant method is to measure the responses of the native biota to the exposure. Particularly for the large-scale ecological studies (i.e., watersheds and reservation-wide studies), it is feasible to monitor the stivte of the biota and compare it to reference sites (Kaputska et al. 1989). Biological survey data represent appropriate species and life stages exposed to the actual mixtures of contaminants in their bioavailable forms on the actual spatial and temporal scales. However, interpretation of such data is complicated by confounding variables and by the imprecision of biological survey methods. For example, if a waste site is largely free of vegetation, and a stream draining the site has few fish, toxicity of the wastes may be responsible; or operation of the waste site may have left the site covered with a compacted low-fertility subsoil, and the stream may be ephemeral or heavily silted.

If biological survey data can be obtained, it will be possible to employ an approach that is analogous to epidemiological studias, of human health effects. Only an epidemiological iype of assessment has the potential to rove that an effect has been caused by waste chemicals. This approach will be adopted only if the screening assessments indicate a potential cause for ecological concern at the site, or if adequate biological data exist from prior monitoring programs. This approach uses the data from the biological surveys that are indicative of effects and supporting data to answer the followit.g two questions.

\section{Are assessment endpoints exceeded?}

Given the existing evidence, is it likely that nonhuman populations exposed to the site's emissions are significantly deleteriously affected? This question may be addressed in two ways. The most direct way would be to measure effects on abundances or production of populations. However, this would require comparisons with the "normal" state at reference sites, and natural temporal and spatial variance in abundance tends to mask small effects and may even mask large effects. The utility of this approach varies among species and sites. For example, plants can be counted much more easily than fish, and fish can be counted much more accurately in streams than in large rivers.

It is not practical to detect a $20 \%$ reduction in abundance or production for some endpoints and habitats. For example, it is not practical to census fish in large rivers such as the Clinch and Ohio rivers (Sect. 4.4). In such cases, indirect means of estimating effects on assessment endpoints are used. Organismal or suborganismal indicators of effects, iniluding growth rates, age distributions, condition, and ova development, are measured in tise field (Adams 1990). Models or expert judgement may then be used to estimate population-level effects from these data.

\section{What is the cause of the effects?}

Establishing that the effects, if any, are caused by the site's emissions will be based on weight of evidence. That is, the evidence must be stronger for causation by the waste-site emissions than for causation by nonpoint sources other than the waste sites (e.g., pesticide use), physical disturbance of the habitat, or natural causes. Evidence concerning causation includes the nature of the effects (e.g., are sensitive species more affected than resistant species?), body burdens of chemicals or biomarker levels, concentrations of chemicals in 
ambient media, and routes of transport of chemicals from the waste site to the point of exposure.

Although it is not necessary to prove causation, it is desirable; and even if causation is not proved, it is helpful to be aware of the evidence required for proof of causation. That is, standards of proof provide a framework for organizing the evidence concerning causation. In epidemiological studies, proving causation requires satisfying Koch's four postulates. Since proving that damage to ecosystems is caused by a particular pollutant is analogous to proving that a disease has a particular cause, the following adaptations of Koch's postulates are applicable (Adams 1963, Woodman and Cowling 1987, Suter 1990a).

1. A regular association must be established between the effects and the source. This requires that a particular effects syndrome be identified and that the syndrome be found regularly in organisms exposed to emissions from the site and not in organisms that are free from exposure.

2. The organisnus that display the effects must also show evidence of exposuie (i.e., body burdens or biomarkers of exposure).

3. The pollutants must be shown to induce effects in controlled exposures (i.e., toxicity tests). To establish the toxicity of existing media, three types of test data may be used: (a) ambient toxicity tests may be performed by caging or planting organisms on the site and on reference sites, (b) the toxicity of these whole media can be tested in the laboratory, or (c) existing test data for individual chemicals may be used. If toxicity is demonstrated in ambient tests or laboratory media tests, it is desirable to determine which contaminants are responsible for the toxicity. This can be done by comparing concentrations of chemicals in the media to existing toxicity data; by fractionation of the medium and testing of the fractions; or by testing spiked site water, sediment, or soil.

4. To establish the relevance of the controlled exposures to the observed effects in the field, it should be shown that the same effects occur at similar levels of exposure in the laboratory and field.

If there is good evidence that the assessment endpoints are being affected in the field, but this analysis indicates that the effects are not attributable to direct toxic effects of the wastes, then other causes should be considered. In particular, toxic effects on foodchain organisms, toxic effects from other sources, and physical disturbance of the habitat should be investigated. If the wastes cannot be proved to be the direct or indirect cause of apparent ecological effects and no other cause can be shown to be operating, then professional judgement must be employed to attribute causation.

\subsection{DETERMINING THE MAGNITUDE AND EXTENT OF ECOLOGICAL EFFECTS}

Once it has been established that a site is causing ecological effects, the baseline risk assessment must estimate the uitimate consequences of a no-action alternative. In order to evaluate consequences, it is necessary to describe the magnitude and extent of ecological effects at the site. 
The magnitude and extent of ecological effects might be examined in a variety of ways, depending on the nature of the effects and the data supporting the attribution of effects to effluents from the site. If population endpoint effects are measured in the field, then the problem is to describe the distribution of those effects in space relative to concentrations of individual pollutants or indices of multiple pollutant exposure (e.g., sum of toxic units, biomarker levels). If effects estimates are based on suborganismal or organismal-level effects measured in the field or on toxicity tests, then the relationship between the lower-level effects and the population-level endpoints must be established before the distribution of these effects can be described.

The above description of methods for estimating the magnitude and extent of effects in the baseline risk assessment is based on the assumption that exposure and effects will not increase through time. This assumption is reasonable for most DOE-OR ER sites because they are old enough for transport of contaminants from points of disposal to ambient media to have occurred. Even without remedial actions, future exposure and effects levels will, in general, decline due to degradation, dilution, and burial in deep sediments. In such cases, the current condition is a conservative basis for the baseline assessment.

For recently active sites or sites that for some other reason are causing increased contamination of ambient media, the magnitude and extent of effects must be estimated from estimates of future distributions of the contaminants. These distributions must be estimated from the output of transport and fate models. Effects of the resulting exposures must be estimated from the exposure-response relationships for the contaminants developed from the assessments of the existing contamination. The relationships may be based on ecotoxicological benchmarks, ambient toxicity tests, biological surveys, or an integration of these alternate approaches.

\section{DEVELOPING BENCHMARK VALUES FOR ECOLOGICAL, RISK}

The screening of contaminants requires the development of an equivalent to the reference toxicity values of the human health risk assessment to separate potentially hazardous concentrations from de minimis concentrations. These ecological benchmark values are also useful for determining whether observed chemical concentrations pose risks to the biota (i.e., the chemical-specific assessment approach) or are likely to be the causes of observed toxicity or effects (i.e., the toxicity testing and biological survey approaches).

The following possible benchmarks (estimators of concentrations corresponding to assessment endpoints) will be considered, and are listed in order ranging from the most conventional and least predictive to the least conventional and most predictive.

1. NWQC. Acute NWQC correspond to one-half of concentrations that would cause $50 \%$ mortality in 5\% of exposed populations. The chronic NWQC are based on a threshold for statistical significance rather than biological significance in a "chronic" toxicity test. Chronic NWQC are the only benchmarks that have been frequently used in ecological 
risk assessments of hazardous waste sites. They are ARARs and de facto standards against which other estimators can be judged. However, the NWQC have major deficiencies.

a. They are not estimates of risk.

b. They are not consistently protective and may be grossly underprotective for some chemicals.

c. They are not available for many chemicals.

d. They do not address sediment or terrestrial exposures.

e. They do not consider the cumulative effects over the life cycle of fish and aquatic invertebrates.

f. They do not always consider the most sensitive response parameter. In particular, effects on fecundity are seldom considered in the toxicity tests used to calculate NWQC.

2. Caniaminant concentrations that result in an $x \%$ reduction in the mast sensitive response panameter. For example, if larval mortality is the most sensitive response parameter, the benchmark value would be a concentration that causes an $x \%$ reduction in the larval survivorship. These benchmarks would be the same as the chronic values used in the NWQC except that biological effects levels would be used rather than statistical significance levels. They could also be used to calculate a final acute:chronic ratio that could then be used to calculate a biologically significant final chronic value to replace the statistically significant final chronic value in the NWQC.

3. Contaminant concentrations that result in an $x \%$ reduction in production in a chronic taxicity rest (e.g., weight of juveniles per initial female). This approach would combine measures of growth, survivorship, and reproduction into a measure of production of the laboratory test population over the course of the test. As with option 2, it could be used directly as a benchmark, or could be used to calculate a biologically significant final chronic value.

4. Contaminant concentrations that result in an $x \%$ reduction in estimated praduction or abundance of a field population. This approach would combine the laboratory data with a population or ecosystem model to actually estimate the proposed endpoint.

The best benchmark value could be chosen from among these alternatives on a case-bycase basis, one preferred alternative could be chosen for all cases, or the most conservative (lowest) value could be chosen for each case. 


\section{RISK CHARACTERIZATION}

The final step in the risk assessment is the characterization of the results of the risk analysis to present to the risk manager and the public. Risk characterization should incli te estimates of the risks to each endpoint, their spatial distribution, and their significance in terms of time-to-recovery or other hazards to which the endpoint resources are exposed. It should also provide an integrated view of the evidence, including discussions of the sources and quality of the data and models used, key assumptions, alternate lines of evidence, and uncertainties. 


\section{THE INTERFACE BETWEEN ECOLOGICAL AND HUMAN HEALTH RISK ASSESSMENTS}

Because the EPA now places equal emphasis on assessing the potential impacts of hazardous waste sites on human health and on environmental health, human health assessments and ecological assessments will be performed concurrently at DOE-OR ER sites. Some information and data are likely to be relevant for assessing both human and environmental threats. Common data needs will be identified during project scoping, and sampling plans will be developed in such a way as to avoid duplication of efforts. It is imperative that human health and ecological risk assessors coordinate their activities and communicate throughout the whole process so that all relevant data are accessible to all parties concerned.

Common data needs for assessing threats to human and environmental health will be determined by the individual characteristics of the site and by the scale of the assessments. From the organizational plan described above (Sect. 4.1), it is clear that sampling efforts for most OUs will be directed primarily towards human health assessments, while the watershed and reservation-wide efforts will be used to a large degree to address ecological issues. It is at the intermediate spatial scale, predominantly the watersheds, that the human health/ecological interface will be most critical, although the interface wiil have to be considered in some fashion at all levels.

In general, the following data needs are likely to be useful for both human health and eculogical risk assessments. Differences between ecological and human health effects data needs are noted in parentheses.

1. Contaminant concentrations in certain media, including

a. soils/sediments (concentrations in the pore water will be required for ecological risk assessments);

b. surface water (concentrations of dissolved forms of cartaminants will be required for ecological risk assessments);

c. groundwater;

d. air; and

e. biota, including fish (whole body concentrations will be required for ecological risk assessments), geese, and deer (endpoint species not in the human food chain such as great blue herons).

2. Chemical inventories.

3. Operational history and current practices at the site.

4. Factors affecting fate and transport of contaminants. For example,

a. physical parameters (e.g., hydrogeologic setting, soil properties, and topography) and

b. bioaccumulation factors, particularly for exposure pathways involving indirect exposures to humans via the food chain.

5. Background concentration data.

All of these factors will be considered as possible common data needs during project scoping. 
In some cases, ecological assessments may require samples to be analyzed in a specific way. The above list notes that sediment pore water concentrations are required for ecological risk assessments. In addition, minimum required detection limirs may be lower for ecological concerns than for human health concerns in some cases. Contaminants that pose a greater threat to ecological rather than human health will need to be analyzed with more precision than would otherwise be required. Certain water quality parameters, such as $\mathrm{pH}$ and oxygen levels, are also more important for ecological assessments.

ithe fact that ecological and human health risk assessments have common data needs will be considered during the prioritization of sites for risk assessments. For example, a site of low ecological priority would not normally require an immediate environmental evaluation. If, however, the site is of immediate concern for human health reasons, it would be advantageous to also evaluate the ecological impacts immediately, at least in the form of a screening level assessment. This is especially true because the analysis of remedial action alternatives must consider both ecological and human health impacts from those alternatives. 


\section{IMPLEMENTATION}

\subsection{DEVELOP BENCHMARK VALUES FOR CONTAMINANTS OF CONCERN AT DOE-OR ER SITES}

The process of developing ecotoxicological benchmark values will involve much scientific judgmeni in deciding which toxicity data are most appropriate, what exposure levels best approximate endpoints, and what, if any, safety factors or correction factors should be applied. The off-site Clinch River ecological screening risk assessment (Suter 1990b) developed tentative be achmark values for a large number of contaminants, but these values need to be better documented and refined. In addition, these benchmarks are applicable only to aquatic communities. Equivalent benchmarks need to be developed for exposure to contaminated soil.

Many contaminants at DOE-OR ER sites have already been prioritized for human health toxicity development on the basis of their frequency of occurrence at DOE-OR ER sites and on whether they have been released to the off-site environment. This list of prioritized contaminants will also be used to prioritize the development of benchmark values for ecological assessments.

The alternate benchmark values discussed in Sect. 6.3 are being developed for high priurity chemicals. These will be used as examples in discussions with the EPA. When EPA concurrence with a particular method is obtained, benchmark values derived by that method for the high priority chemicals will be used. All future benchmarks will be derived using the EPA-approved method. The benchmarks will include a set of two values for each contaminant and medium: an upper bound that, if exceeded, indicates cause for immediate concern, and a lower bound that, if not exceeded, indicates nu need for further concern.

\subsection{COMPARE ECOLOGICAL AND HUMAN HEALTH BENCHMARKS}

Remedial investigations have emphasized risks to human health in part because of the lack of guidance for ecological risk assessment, and in part because of a perception that protection of human health will be sufficient to protect the nonhuman environment. The latter may not be true for a number of reasons. Many of the NWQC for aquatic life are lower than those for human health. Elevated levels of some chemicals, such as ammonia, chlorine, and aluminum in drinking or bathing water, may pose no risk or negligible risk to humans while causing mass mortality of aquatic organisms. Depressed dissolved oxygen levels can also cause severe mortality amongst aquatic organisms. Some chemicals are inherently more toxic to nonhuman organisms due to modes of action that do not occur in humans (e.g., eggshell thinning by DDT metabolites) or for unknown reasons (e.g., lethality due to chlorinated dibenzo-dioxins). There are also modes of action at the ecosystem level, such as eutrophication by nutrients and blockage of light by suspended sediments, that have no analog in human health effects. In some cases the greater nonhuman risk is due to routes of exposure that are not credible for humans, such as respiring water, drinking from waste sumps, oral cleaning of the pelt or plumage, and root uptake. Finally, even when modes of action and routes of exposure are the same, nonhuman organisms commonly receive a much higher dose than humans. For example, humans eat a few fish meals a week, while a heron 
eats very little other than fish and eats the whole fish, not just the relatively uncontaminated muscle.

As benchmark values for ecological endpoints ar developed, they will be compared to equivalent human health values (taking into consideration differences in exposure) to determine which contaminants at a principally of human health concern, which are principally of ecological concern, and which may constitute either a greater human health risk or a greater ecological risk, depending on the nature of the site. Although the identification of a certain chemical as being of greater human health concern at a site will not lead to its rernoval from the ecological assessment (or vice-versa), it will allow a prioritization of activities for assessing and remediating the more important risks. Furthermore, contaminants of greater ecological concern may require the use of special analytical laboratory techniques in order to achieve lower detection limits than would be required for human health purposes. 


\section{REFERENCES}

Adams, D. F. 1963. Recognition of the effects of fluorides on vegetation. J. Air Pollut. Control Assoc. 13:360-362.

Adams, S. M. (ed.). 1990. Biological Indicators of Stress in Fish. Amer. Fish. Soc., Bethesda, Maryland.

Anderson, S. L., and T. J. NCrberg-King. 1991. Precision of short-term chronic toxicity tests in the real world. Environ. Toxicol. Chem. 10:143-145.

Barnthouse, L. W., G. W. Suter II, and A. E. Rosen. 1990. Risks of toxic contaminants to exploited tish populatio as: Influence of life history, data uncertainty, and exploitation intensity. Environ. Toxıcol. Chem. 9:297-311.

EPA (U.S. Environmental Protection Agency). 1989. Risk assessment guidance for superfund: Volume II, Environmental evaluation manual. EPA/540/1-89/001. Office of Emergency and Remedial Response.

EPA (U.S. Environmental Protection Agency). 1990. Biological criteria: National program guidance for surface waters. EPA-440/5-90-004. Office of Water, Washington, D.C.

Environmental Restoration Division. 1992. Oak Ridge Reservation site management plan for the Environmental Restoration Program. DOE/OR-1001/R2. Oak Ridge, Tennessee.

Greene, J. C., C. L. Bartels, W. J. Warten-Hicks, B. R. Parkhurst, G. L. Linder, S. A. Peterson, and W. E. Miller. 1988. Protocols for short-term toxicity screening of hazardous waste sites. U.S. Environmental Protection Agency, Corvallis, Oregon.

Kaputska, L., T. LaPoint, J. Fairchild, K. McBee, and J. Bromenshenk. 1989. Field assessments. pp. 8-1-8-88. In W. Warren-Hicks, B. R. Parkhurst, and S. S. Baker, Jr. (eds.), Ecological assessment of hazardous waste sites: $A$ field and laboratory reference document. EPA 600/3-89/013. Corvallis Environmental Research Laboratory, Oregon.

Office of Pesticide Programs. 1982. Pesticide assessment guidelines, Subdivision E, Hazard evaluation: wildife and aquatic organisms. EPA-540/9-82-024. U.S. Environmental Protection Agency, Washington, D.C.

Office of Policy Analysis. 1989. Summary of ecological risks, assessment methods, and risk management vecisions in Superfund and RCRA. EPA-230-03-89-046. U.S. Environmental Protection Agency, Washington, D.C.

Parkhurst, B., G. Linder, K. McBee, G. Bitton, B. Dutka, and C. Hendricks. 1989. Toxicity tests. pp. 6-1-6-66. In W. Warren-Hicks, B. R. Parkhurst, and S. S. Baker, Jr. (eds.), Ecological assessment of hazardous waste sites: $A$ field and laboratory reference. EPA/600/3-89-013. Environmental Protection Agency, Corvallis, Oregon.

Reilly, W. K. 1990. Aiming before we shoot: the quiet revolution in environmental policy. 20Z-1011. U.S. Environmental Protection Agency, Washington, D.C.

SAB (Science Advisory Board). 1990. Reducing risk: setting priorities and strategies for environmental protection. SAB-EC-90-021. U.S. Environmental Protection Agency, Washington, D.C.

Suter, G. W., II, A. E. Rosen, E. Linder, and D. F. Parkhurst. 1987. Endpoints for responses of fish to chronic toxic exposures. Environ. Toxicol. Chem. 6:793-809.

Suter, G.W., II. 1989. Ecological endpoints. pp. 1-2-2-28. In W. Warren-Hicks, B. R. Parkhurst, and S. S. Baker, Jr. (eds.), Ecological assessment of hazardous waste sites: A field and laboratory reference. EPA/600/3-89-013. Environmental Protection Agency, Corvallis, Oregon. 
Suter, G. W., II. 1990a. Use of bionnarkers in ecological risk assessment. pp. 419-426. In J. F. McCarthy and L R. Shugart (eds.), Biomarkers of Environmental Contamination. Lewis Publishers, Boca Raton, Florida.

Suter, G. W., II. 1990b. Screening level risk assessment for off-site ecological effects in surface waters downstream from the U.S. Department of Energy Oak Ridge Reservation. ORNL/ER-8. Oak Ridge National Laboratory, Environmental Sciences Division, Publication No. 3483.

Vaughan, D. S., and W. Van Winkle. 1982. Corrected analysis of the ability to detect reductions in year-class strength of the Hudson River white perch (Morone americana) population. Can. J. Fish. Aquat. Sci. 39:782-785.

Warren-Hicks, W., B. R. Parkhurst, and S. S. Baker, Jr. (eds.). 1989. Ecological assessment of hazardous waste sites: $A$ field and laboratory reference. EPA/600/3-89-013. Environmental Protection Agency, Corvallis, Oregon.

Woodman, J. N., and E. B. Cowling. 1987. Airborne chemicals and forest health. Environ. Sci. Technol. 21:120-126. 
ES/ER/TM-33

\section{DISTRIBUTION}

1. L. D. Bates

2. L. W. Barnthouse

3. B. G. Blaylock

4. R. R. Bonzcek

5. J. B. Cannon

6. R. B. Cook

7. J. H. Cushman

8. M. F. P. DeLozier

9. K. F. Eckerman

10. D. E. Fowler

11. C. W. Gehrs

12. C. D. Goins

13. P. J. Halsey

14. S. G. Hildebrand

15. F. O. Hoffman

16. R. M. Hull

17. P. Kanciruk

18. B. L. Kimmel

19. R. Kramel

20. V. Legg

21-23. D. M. Matteo

24. C. W. McGinn

25. D. B. Miller

26. D. Miller

27-28. P. T. Owen
29. S. T. Purucker

30-31. A Redfearn

32. D. E Reichle

33. G. E. Rymer

34. P. A. Schrandt

35. F. E. Sharples

36-37. R. A. Shaw

38. D. S. Shriner

39. J. L. Skiles

40. M. E. Stack

41. S. H. Stow

42-46. G. W. Suter

47. K. B. Swain

48. D. W. Swindle

49. C. C. Travis

50. R. I. Van Hook

51. D. R. Watkins

52-53. R. K. White

54. Central Research Library

55-59. ER Document Management Center

60-64. ESD Library

65-66. Laboratory Records Dept.

67. ORNL Patent Section

68. ORNL, Y-12 Technical Library

69. Office of Assistant Manager for Energy Research and Development, DOE Oak Ridge Field Office, P.O. Box 2001, Oak Ridge, TN 37831-8600

70. J. F. Franklin, Bloedel Professor of Ecosystem Analysis, College of Forest Resources, University of Washington, Anderson Hall AR-10, Seattle, WA 98195

71. R. C. Harriss, Institute for the Study of Earth, Oceans, and Space, Science and Engineering Research Building, University of New Hampshire, Durham, NH 03824

72. G. Y. Jordy, Director, Office of Program Analysis, Office of Energy Research, ER-30, G-226, U.S. Department of Energy, Washington, JC 20545

73. R. L. Nace, Department of Energy, Office of Environmental Restoration, Office of Eastern Area Programs, Oak Ridge Program Division, Washington, DC 20585-0002

74. R. H. Oisen, Professor, Microbiology and Immunology Department, University of Michigan, Medical Sciences II, \#5605, 1301 East Catherine Street, Ann Arbor, MI 48109-0520

75. A. Patrinos, Acting Director, Environmental Sciences Division, Office of Health and Environmental Research, ER-74, U. S. Departm znt of Energy, Washington, DC 20585 
76-77. R. C. Sleeman, DOE Oak Ridge Field Office, P.O. Box 2001, Oak Ridge, TN 378318541

78-79. J. T. Sweeney, DOE Oak Ridge Field Office, P.O. Box 2001, Oak Ridge, TN 378318541

80. D. W. Swindle, Radian Corporation, 120 South Jefferson Circle, Oak Ridge, TN 37830

81. J. Tate, ERCE, 800 Oak Ridge Turnpike, Jackson Plaza, Suite 103, Oak Ridge, TN 37830

82. W. Tolbert, Project Manager, SAIC, 301 Laboratory Rd., Oak Ridge, TN 37830

83. F. J. Wobber, Environmental Research, ER-74, U.S. Department of Energy, Washington, DC 20585

84. F. Zatran, Senior Environmental Scientist, SAIC, 8400 Westpark Dr., McLean, VA 22102

85-86. Otfice of Scientific and Technical Information, P.O. Box 62, Oak Ridge, TN 37831 

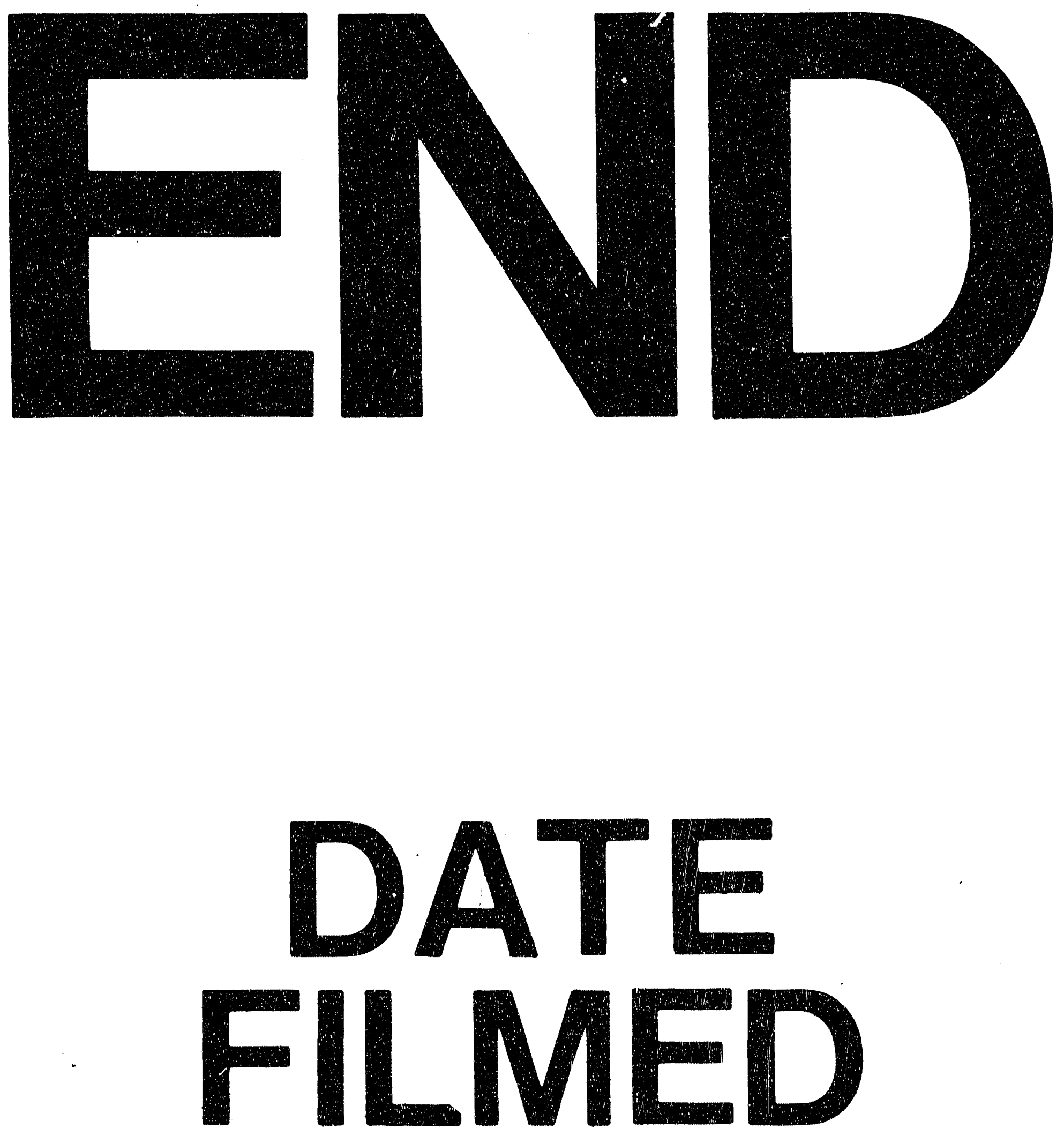

章

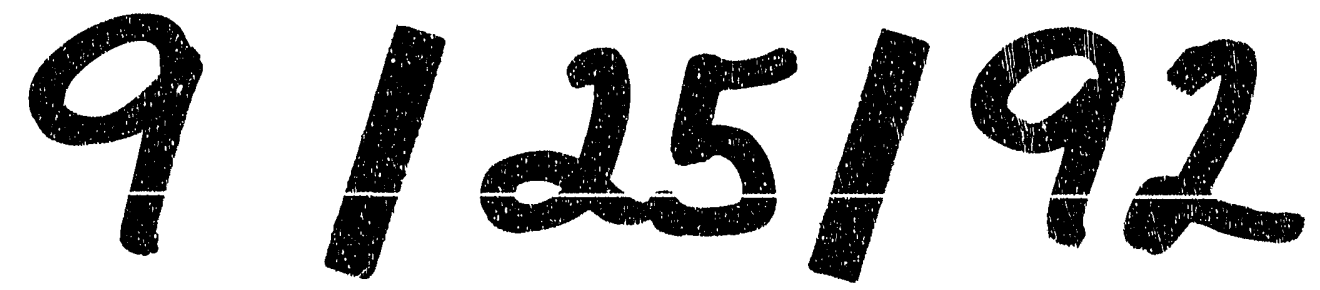


